\title{
Apresentação
}

Enrique Serra Padrós*

\section{Ditaduras de Segurança Nacional no Cone Sul}

O Dossiê Ditaduras de Segurança Nacional no Cone Sul, que integra o presente número da Revista Anos 90, confirma o crescimento e a excelência das pesquisas que, sobre essa temática, vêm sendo realizadas nos países do Cone Sul. Nesse sentido, o avanço da produção historiográfica é inegável. Tal fato decorre, por um lado, de uma certa mirada simultânea na valorização da História Recente regional; por outro, pelo contexto de mudanças políticas na região, fato que não é alheio à revalorização do passado imediato. Nesse sentido, há, no presente, o interesse social pelo resgate da experiência histórica de uma geração que viveu singularmente aquele período autoritário, bem como uma agenda de demandas sobre questões inconclusas (abertura de arquivos repressivos; papel da justiça; reparações; formação de comissões da verdade etc.). Tais demandas redimensionam as contribuições que os historiadores e profissionais de outras áreas geram a partir das suas pesquisas e dos seus trabalhos de divulgação, permitindo, ainda, a socialização de um conhecimento que possibilita à sociedade maior aproximação a um passado ainda pouco conhecido e interditado por controversas políticas de esquecimento.

Deve-se salientar, também, que uma perspectiva de conjunto sobre o Cone Sul - independentemente dos traços singulares que,

* Professor do Departamento e Programa de Pós-Graduação em História da UFRGS. 
evidentemente, emolduram as experiências locais e nacionais - possibilita desenvolver uma percepção dos elementos comuns, paralelos, semelhantes e, em diversos casos, conectados. $\mathrm{O}$ atual panorama político dos países da região tem estimulado o debate sobre leis de anistia, acessibilidade dos arquivos repressivos, comissões de verdade e justiça de transição, papel das testemunhas, herança das experiências traumáticas e formas de reparação, bem como avanços e recuos do Poder Judiciário diante dos crimes do terrorismo de Estado. Portanto, não só a academia tem se mostrado receptiva a esta dinâmica efervescente em relação à história recente, como outros protagonistas têm incidido no debate, caso de partidos políticos, associações de direitos humanos, mídia, forças armadas etc., gerando um vigoroso processo de interação que é retroalimentado pela simultaneidade de iniciativas tão diversas, mas que coincidem em um redimensionamento e valorização do passado recente.

O conjunto de quatorze artigos e uma resenha que compõem o Dossiê (resultado de exigente processo seletivo que envolveu mais de trinta e cinco artigos recebidos) reflete as problemáticas anteriormente citadas, incluindo aspectos vinculados aos antecedentes e às transições posteriores, enfatizando diversos subtemas correlatos: fontes e arquivos; fundamentação doutrinária; conexão repressiva; discussões teóricas; papel da memória; efeitos traumáticos etc.

O Dossiê inicia com a apresentação de um consistente artigo do professor Bruno Groppo, pesquisador do Centre d'Histoire Sociale du XXe Siècle (Université de Paris I). Intititulado Reflexões sobre os conceitos de responsabilidade e culpa na obra de Karl Jaspers e sobre sua aplicabilidade à ditadura de 1976-1983 na Argentina, o texto analisa a tentativa do filósofo alemão de propor, em 1946, portanto, no contexto do julgamento e da divulgação massiva dos crimes cometidos pelo nazismo, uma avaliação à sociedade alemã, sobre a sua atitude, participação ou omissão diante daquela experiência. A análise de Groppo resgata a proposição de Jaspers, de estabelecer um debate centrado nos conceitos de responsabilidade e culpa. Ignorada no seu tempo, a problemática ética levantada pelo filósofo alemão, entretanto, acabou sendo recolocada pelos filhos da geração do silêncio. Diante dos significativos efeitos que, finalmente, produziram tais ideias de Jaspers, Groppo utiliza esse antecedente para aferir 
se contribui para dar maior inteligibilidade ao tenso embate entre esquecimento e memória existente na história argentina relacionado à ditadura de 1976-1983.

$\mathrm{O}$ artigo La dictadura del Proceso de reorganización nacional y la represión al movimiento obrero, de autoria do professor da UBA, Pablo Pozzi, centra-se em um dos objetivos mais estratégicos - e ainda pouco conhecido - da ditadura de segurança nacional argentina, a repressão contra o movimento operário, condição fundamental para seu disciplinamento e para a reprodução do capital. Com o objetivo de abrir a economia e torná-la competitiva, procurou-se acabar com o ativismo sindical. A infiltração, a delação e a colaboração orgânica entre setores empresariais e forças repressivas foram fundamentais para atingir aqueles objetivos. Pozzi expõe os mecanismos de enquadramento específicos implementados pela ditadura, caso dos sequestros e desaparecimentos ocorridos em empresas como a Ford e a Mercedes Benz, entre outras. A partir da explicitação da análise da documentação produzida pela Dirección de Investigaciones Políticas de la Policía de la Provincia de Buenos Aires, o autor destaca, ainda, a utilização de leis que permitiram garantir algum grau de legitimidade, bem como a imposição de uma reestruturação sindical que permitiu cooptar quadros dirigentes, tirando autonomia e capacidade reivindicativa ao movimento e isolando, assim, os setores mais organizados do denominado sindicalismo combativo.

O Golpe civl-militar de 64: algumas possibilidades sobre seu significado, artigo do cientista político e professor da Universidade Católica de Pelotas, Renato Della Vecchia, apresenta um panorama das condições que geraram a interrupção da democracia brasileira em 1964. Partindo de certas interpretações clássicas sobre o significado histórico do golpe, entre as quais as realizadas por Paul Singer, Maria Victória Benevides, Angelina Cheibub Figueiredo, Fernando Henrique Cardoso e José Serra, Della Vecchia avalia o desenrolar do processo histórico que configura a queda do Governo Goulart, a partir da premissa do necessário diálogo do político com o econômico, como chave explicativa para compreender as expectativas então existentes em relação ao sentido e significado de tão frágil democracia, e do autoritarismo em gestação.

Anos 90, Porto Alegre, v. 19, n. 35, p. 13-22, jul. 2012 
A atuação parapolicial é o tema desenvolvido por Ana Belén Zapata, da Universidad Nacional del Sur (Bahía Blanca), em Violencia parapolicial en Babia Blanca, 1974-1976. Delgados límites entre lo institucionaly lo ilegal en la lucha contra la "subversión apátrida". Ancorada nos documentos existentes no Arquivo da Dirección de Inteligencia de la Policía de la Provincia de Buenos Aires (DIPBA), o trabalho analisa aspectos da violência implementada por grupos parapoliciais na cidade de Bahía Blanca (provincia de Buenos Aires), entre os anos de 1974 e 1976. Trata-se do período de amadurecimento e fermentação dos fatores que levaram ao golpe de Estado que impôs a ditadura identificada com o Proceso de Reorganización Nacional. Centrado na violência de extrema direita naquela cidade, o artigo indaga a respeito das motivações e caracterização dos crimes promovidos na fase terminal da tensa democracia argentina, o grau de conhecimento e envolvimento da própria DIPBA (órgão estatal) e a forma como os protagonistas do sistema político encararam e interpretaram essas ações ilegais e parapoliciais na denominada "luta antissubversiva" instalada previamente ao próprio golpe de Estado.

O texto de Débora Carina D'Antonio - Los presos políticos del penal de Rawson: un tratamiento para la desubjetivación Argentina (19701980) - foca, de uma perspectiva de gênero, a realidade de um centro de detenção onde foi aplicada uma tecnologia de disciplinamiento, sob o marco de práticas evidentemente ilegais e inconstitucionais. Segundo a autora, no interior da prisão de Rawson, foi imposta uma lógica desmasculinizadora que extrapolou o objetivo explícito da ditadura de quebrar os presos de uma perspectiva ideológica e política. O artigo, ao introduzir o tema da violência sexual, perfila-se como instrumento de resgate de traumas ainda pouco explicitados que confirmam a existência de faces repressivas ainda pouco conhecidas dentro do inesgotável universo constitutivo do terrorismo de Estado. Mesmo assim, onde a atuação da justiça é perceptível, coletivos de vítimas que sofreram essa violência vêm ocupando espaço público e colocando o problema como temática necessária de pesquisa ou experiência de vida que exige reparações e responsabilizações. É da natureza dessa dimensão tão complexa, portanto, que trata a reflexão de D’Antonio. 
A professora Paula Vera Canelo, pesquisadora do Conicet e da Universidad Nacional de San Martín, questiona no seu artigo Los desarrollistas de la 'dictadura liberal'. La experiencia del Ministerio de Planeamiento durante el Proceso de Reorganización Nacional en la Argentina, a caracterização da ditadura argentina (1976-1983), certa compreensão generalizada que associa a ditadura argentina (1976-1983) como sendo homogeneamente liberal. Após historiziçar a experiência de planejamento no país e apontar uma linha de continuidade desde o governo Frondizi até o golpe do Proceso de Reorganización Nacional, Canelo, discordando daquele senso comum, avalia a pugna interna entre o entorno do Ministro de Economia, Martínez de Hoz (aperturista, privatista e desindustrializador), e um conjunto civil-militar que, através do Ministério do Planejamento e desempenhando funções no complexo militar industrial e em empresas estatais, defendia o planejamento e a intervenção estatal na economia, a partir de uma interpretação da Doutrina de Segurança Nacional, que justificava uma "industrialização defensiva" e que se estabelece no interior do aprofundamento da relação do binômio "desenvolvimento-modernização". O artigo estuda a origem e formação doutrinária desse grupo, sua inserção no projeto ditatorial, o embate com correntes opostas e seu declive final.

Alejandro Paredes, pesquisador do Conicet e da Universidad Nacional de Cuyo (Mendoza) centra seu artigo, La organización de los refugiados politicos chilenos en Mendoza y la buelga de hambre de Julio de 1976, na conexão repressiva regional chileno-argentina, destacando o caso dos refugiados políticos chilenos, em Mendoza (Argentina), entre 1976 e 1983. Após o golpe no Chile, milhares de perseguidos políticos chilenos e de outras nacionalidades fugiram do Chile, da Unidade Popular, atravessando a duras penas a cordilheira dos Andes, a procura de "terra amiga". A implantação da ditadura na Argentina, em 1976, aprofundaria o clima de hostilidade contra esses exilados, inclusive dentro do marco da Operação Condor. A partir do dimensionamento de uma greve de fome promovida em 1976, Paredes resgata uma história de resistência e solidariedade, em condições extremadas. A mesma teve como protagonistas diretos, além de milhares de refugiados chilenos, a organização cristã

Anos 90, Porto Alegre, v. 19, n. 35, p. 13-22, jul. 2012 
Comitê Ecumênico de Ação Social (CEAS), amparada e financiada pelo Conselho Mundial de Igrejas e pela ACNUR.

Jorge Fernández, professor da Universidade Federal do Mato Grosso do Sul e pesquisador das relações repressivas argentinobrasileiras no contexto das ditaduras de segurança nacional, no texto O Brasil e a Contra-ofensiva Montonera, 1978-1980, perscruta a forma como a Operação Retorno, conhecida como Contraofensiva Montonera, permitiu a coordenação de esforços entre as ditaduras do Brasil e da Argentina tentando impedir que o território do primeiro fosse utilizado como caminho ou plataforma para a passagem dos militantes que, após avaliação feita pela sua direção no exílio, haviam recebido ordens de retomar a luta armada no seu país. A pesquisa de Fernández, assentada em documentos repressivos, mapeia rotas e locais de passagem dos quadros montoneros. Da mesma forma, identifica a informação que circulava entre as forças de segurança de ambas ditaduras e avalia o grau de infiltração que sofria a organização armada. Finalmente, contribui no problemático resgate dos acontecimentos que produziram o desaparecimento de cidadãos argentinos no Brasil, bem como os coloca dentro da perspectiva da coordenação regional da Operação Condor.

Também relacionado com o tema da conexão repressiva regional, o artigo da doutoranda Melisa Slatman, denominado Actividades extraterritoriales represivas de la Armada Argentina durante la última dictadura de Seguridad Nacional (1976-1981), realça o protagonismo da Marinha argentina. A partir de um conjunto de apreciações reflexivas sobre a essência da já citada Operação Condor, o texto defende a necessidade de aprofundar o debate sobre a mesma, a efeitos de aprimorar sua conceituação. Dessa forma, marca distância, de uma perspectiva problematizadora à luz de pesquisas empíricas mais recentes, dos primeiros trabalhos de investigação e sua ênfase em uma certa linearidade de atuação dos protagonistas envolvidos. Tomando como objeto de estudo as atividades repressivas extraterritoriais da Marinha durante a última ditadura de segurança nacional na Argentina, Slatman investiga a inserção das mesmas no marco institucional do Estado Terrorista. A seguir, analisa a constituição e autonomização, na estrutura orgânica da Marinha, do Grupo de Tareas 3.3, responsável pela administração de um dos maiores

Anos 90, Porto Alegre, v. 19, n. 35, p. 13-22, jul. 2012 
centros clandestinos de detenção do país: a Escuela de Mecánica de la Armada (ESMA). Finalmente, o estudo analisa a evolução das atividades repressivas extraterritoriais desse Grupo de Tareas, dentro do marco multifacêtico da coordenação regional existente.

No artigo $A$ constituição das memórias sobre a repressão da ditadura: o projeto Brasil: Nunca Mais e a abertura da Vala de Perus, a doutora pela Universidade de São Paulo, Janaína Almeida Teles, oferece um panorama reflexivo sobre a interdição do passado recente, estabelecendo uma narrativa sobre a formação da memória social a partir destes momentos "fundacionais", que diluíram e esvaziaram os limites de transição pactuada que marca o cenário pós-ditadura no Brasil. Partindo da constatação de que a transição brasileira para a democracia ocorreu sem rupturas evidentes, o que tem possibilitado a persistência de legado ditatorial, até hoje, a autora considera que a reconstituição factual e a avaliação crítica acerca do período autoritário têm sido permeadas por zonas de silêncio e interdições. Para tanto, escolhe como objeto de análise eventos que, segundo ela, são fundamentais na formação da memória sobre a repressão da ditadura brasileira: a publicação do projeto Brasil: Nunca Mais e a abertura da Vala de Perus. Em relação ao primeiro, além de resgatar a história da sua produção do seu contexto, realiza-se, a partir dele, a avaliação do seu impacto no conjunto da sociedade e a comparação com o Nunca Mais argentino - bem como com o impacto que este gerou no seu país. Quanto à Vala de Perus, o texto é muito rico quanto à análise das dificuldades, dos entraves e das limitações colocadas pelo poder público. Merece registro, ainda, além de outras fontes pertinentes, o rico conjunto de entrevistas com protagonistas diretamente envolvidos nos eventos citados.

Priscila Brandão, professora da Universidade Federal de Minas Gerais, e Isabel Leite, doutoranda da Universidade Federal do Rio de Janeiro, resgatam no artigo Nunca foram heróis! A disputa pela imposição de significados em torno do emprego da violência na ditadura brasileira, por meio de uma leitura do Projeto ORVIL, o processo de criação, execução e divulgação desse controvertido documento. O texto lembra que algumas das afirmações ali contidas têm sido constantemente replicadas no site TERNUMA, com cuja lógica narrativa mantém sintonia. O projeto, esboçado desde o final da 
ditadura, pretendia contrapor-se à narrativa de uma história recente da ditadura produzida pela esquerda sobrevivente acerca da tortura - principalmente a partir da Anistia - e divulgada através de entrevistas, bibliografia memorialística e, sobretudo, do relatório Brasil Nunca Mais, da Arquidiocese de São Paulo. As perguntas das autoras miram na percepção que de se tinha um determinado grupo de militares, marcadamente ultraconservadores e perfilados no centro do processo do golpe de Estado, na implementação dos mecanismos repressivos e nas estratégias utilizadas para contar e rememorar esse passado.

Em Do luto à luta: um estudo sobre a Comissão de Familiares de Mortos e Desaparecidos Politicos no Brasil, o cientista político, Carlos Gallo, analisa a luta da Comissão de Familiares de Mortos e Desaparecidos Políticos (CFMDP), cuja atuação no tempo tem mantido coerência na defesa e exigência dos seguintes eixos reivindicativos: a responsabilização do Estado pelos crimes praticados contra os direitos humanos; a apuração das circunstâncias das mortes e desaparecimentos; a responsabilização dos culpados; e o resgate dos fatos e a preservação da memória relacionada aos mesmos. Incansável, a Comissão tem sido referência no esforço pelo combate ao esquecimento induzido e à impunidade resultante da ação estatal, bem como da omissão de importantes setores da sociedade. Como grupo de pressão, a organização, que carrega as bandeiras históricas do Nunca mais e as exigências de "Verdade, Memória e Justiça", tem ocupado espaço crucial no questionamento das posições do Estado quanto à abertura dos arquivos repressivos, à interpretação sobre a Lei da Anistia, à condenação do Brasil na CIDH/OEA e à demora pela nomeação da Comissão da Verdade. Nesse sentido, o artigo de Gallo analisa o surgimento das demandas dos familiares, a sua organização após a ditadura, o conteúdo das demandas, a forma como a questão dos mortos e desaparecidos foi trabalhada ao longo dos anos e, por fim, os limites às demandas dos familiares durante a sua trajetória.

O artigo Te seguiremos buscando... Derecho a la identidad y prácticas judiciales durante el Terrorismo de Estado en Argentina resulta de um trabalho coletivo multidisciplinar que objetiva um dos temas mais 
candentes, mobilizadores e singulares da experiência argentina de segurança nacional e do terrorismo de Estado: o sequestro de crianças e a apropriação da sua identidade. Trata-se de uma pesquisa desenvolvida no Archivo General de los Tribunales de Córdoba (Argentina), orientada à divulgação, sistematização e análise das adoções tramitadas nos juizados civis e de menores da cidade de Córdoba durante 1975 e 1983. A pesquisa, baseada em fontes judiciais, resgatou a lógica da tramitação dessas adoções, permitindo avaliar a vinculação do poder judiciário com esse crime. Os autores concluem que a falta de exigências legais existentes na época favoreceram tais "adoções" e que o plano sistemático de apropriação ilegal de crianças desenvolvido pela ditadura se apoiou em mecanismos e dispositivos que facilitaram a inscrição de crianças como filhos próprios e que funcionavam como regra no interior dos processos judiciais.

No artigo de Maricel Alejandra López, Moraly don en las reparaciones económicas a las víctimas del terrorismo de estado en Argentina, a autora propõe pensar o tema das reparações a partir da teoria do "don", elaborada por Marcel Mauss. Tal teoria é vista como instrumento que a autora considera válido para superar um debate tensionado pelos valores, pelas ações e pelos compromissos que as vítimas e os sobreviventes remarcam sempre como algo político e ético. López lembra que a reparação econômica às vítimas da ditadura é uma das políticas estatais que o Estado estabeleceu em relação aos crimes cometidos pela ditadura contra os direitos humanos. Mas na lógica das vítimas, a vida, a morte e os direitos humanos são parte das "coisas que não têm preço", embora estejam inseridas em um mundo onde o econômico é sempre relevante. Para muitas das vítimas e dos sobreviventes, toda reparação é algo que não pode ser aceito, pois, supostamente, contradiz valores, coerências e ações. Para López, analisar tais reparações à luz da Teoria do “don”, de Marcel Mauss, pode tornar possível a aceitação do fato da reparação. A base do esquema é o tripé “dar, receber, devolver", em que o "don" é percebido como ato de reconhecimento social, enquanto que o "receber" representa uma carga redimida pelo "devolver".

Por fim, o Dossiê encerra-se com a resenha sobre a obra de Caroline Silveira Bauer, Brasil e Argentina: ditaduras, desaparecimentos e políticas de memória, resultado da tese de doutorado defendida no 
PPG-História da UFRGS, em 2011, e vencedora do Prêmio Teses da FLACSO/CLACSO, em 2012.

Diante de tudo o que foi exposto, agradecemos a todos os autores que encaminharam seus artigos para avaliação, bem como aos pareceristas que muito contribuíram para a qualidade deste Dossiê Ditaduras de Segurança Nacional no Cone Sul que ora apresentamos. Boa leitura. 